\title{
Exigência de aminoácidos sulfurados digestíveis para suínos machos castrados mantidos em ambiente termoneutro dos 15 aos $30 \mathrm{~kg}$
}

\author{
[Digestible sulphurous aminoacid requirement for swine barrows maintained in a thermoneutral \\ environment from 15 to $30 \mathrm{~kg}$ ] \\ R.G.M.V. Vaz $^{1}$, R.F.M. Oliveira
, J.L. Donzele
C. Kiefer ${ }^{1}$, U.S.A.D. Frlando $^{1}$ \\ ${ }^{1}$ Estudante de Pós-graduação - Universidade Federal de Viçosa \\ ${ }^{2}$ Departamento de Zootecnia - Universidade Federal de Viçosa \\ Campus Universitário \\ Av. P.H. Rolfs, s/n \\ 36571-000 - Viçosa, MG
}

\begin{abstract}
RESUMO
Determinou-se a exigência de aminoácidos sulfurados para suínos machos castrados, mantidos em ambiente termoneutro, dos 15 aos $30 \mathrm{~kg}$. Utilizaram-se 70 leitões mestiços, distribuídos em delineamento experimental de blocos ao acaso, com cinco tratamentos $(0,465 ; 0,511 ; 0,558 ; 0,605$ e $0,652 \%$ de metionina + cistina digestível), sete repetições e dois animais por repetição. As rações experimentais e a água foram fornecidas à vontade. A temperatura no interior da sala foi mantida em $21,8 \pm 0,4^{\circ} \mathrm{C}$ e a umidade relativa, em $73,8 \pm 4,9 \%$. Os níveis de metionina + cistina digestível da dieta influenciaram de forma quadrática o ganho de peso diário, que aumentou até o nível de $0,596 \%$, e a conversão alimentar, que reduziu até o nível de $0,627 \%$. O consumo de ração dos animais não variou com os tratamentos. Os tratamentos influenciaram a deposição de proteína na carcaça, que aumentou de forma quadrática até o nível de $0,630 \%$, enquanto a de gordura não variou. A exigência de aminoácidos sulfurados digestíveis para suínos machos castrados, mantidos em ambiente termoneutro, dos 15 aos $30 \mathrm{~kg}$, é de $0,63 \%$, correspondente à relação metionina + cistina digestível:lisina digestível de $67 \%$, para máximo desempenho e composição de ganho.
\end{abstract}

Palavras-chave: leitão, exigência, fase inicial de crescimento, metionina+cistina, termoneutralidade

\begin{abstract}
The requirements of digestible sulphurous aminoacids for swine barrows maintained in a thermoneutral environment from 15 to $30 \mathrm{~kg}$ were estimated. Seventy crossbred barrows were allotted to a completely randomized block design with five treatments $(0.465 ; 0.511 ; 0.558 ; 0.605 ; 0.652 \%$ of digestible methionine+cystine), seven replicates and two animals by replicate. The experimental diets and the water were supplied ad libitum. The inside room temperature was maintained in $21.8 \pm 0.4^{\circ} \mathrm{C}$ and the relative humidity in $73.8 \pm 4.9 \%$. The digestible methionine and cystine levels of the diet had a quadratic effect on average daily gain that increased until the level of $0.596 \%$ and the feed:gain ratio that reduced quadraticaly until the level of $0.627 \%$. No effect of digestible aminoacid on feed intake was observed. The treatments affected protein deposition in the carcass that increased quadraticaly until the level of $0.630 \%$, but had no effect on fat deposition. The digestible sulphurous aminoacids requirement for barrows maintained in a thermoneutral environment from 15 to $30 \mathrm{~kg}$ was $0.63 \%$, which corresponds to
\end{abstract}

Projeto financiado pela AJINOMOTO

Recebido para publicação em 2 de dezembro de 2003

Recebido para publicação, após modificações, em 19 de agosto de 2004

* Autor para correspondência (corresponding author)

E-mail: flavia@mail.ufv.br 
digestible methionine and cystine:digestible lysine ratio of 67\%, respectively, for highest performance and gain composition.

Keywords: barrow, initial growing phase, methionine + cystine, thermoneutrality, requirement

\section{INTRODUÇ̃̃O}

Nos suínos, o balanço entre o ganho e a perda de calor corporal é alcançado pela combinação dos efeitos dos mecanismos termorreguladores fisiológicos e morfológicos e pelo comportamento do animal (Effect..., 1981). Assim, o ambiente no qual o suíno é mantido influencia o consumo voluntário da ração como forma de modificar o calor proveniente de processos digestivos e metabólicos, influenciando, conseqüentemente, o ganho de peso, a taxa de eficiência alimentar e a composição de carcaça.

Os suínos necessitam de quantidades de aminoácidos específicos e não depositam proteína corporal além de sua capacidade fisiológica, sendo o excesso desperdiçado em relação à sua função específica e excretado na urina, na forma de uréia, aumentando o potencial poluente e o custo das formulações (Hedges, 2003). Assim, a otimização das relações dos aminoácidos nas rações resulta em maior utilização do nitrogênio e maior desempenho dos animais, além de reduzir a excreção de nitrogênio dos dejetos (Kerr e Easter, 1995).

A metionina + cistina constituem o segundo aminoácido limitante em rações à base de milho e farelo de soja para suínos. Segundo Loughmiller et al. (1996), esses aminoácidos são usados principalmente para a manutenção do tecido intestinal. Por isso, a determinação de sua exigência, considerando-se o ambiente no qual o animal está inserido, é importante quando a finalidade é maximizar o crescimento e o desenvolvimento dos animais, principalmente de jovens.

Este estudo teve o objetivo de determinar a exigência de aminoácidos sulfurados digestíveis de suínos machos castrados, mantidos em ambiente de termoneutralidade, dos 15 aos $30 \mathrm{~kg}$.

\section{MATERIAL E MÉTODOS}

Foram utilizados 70 leitões machos castrados mestiços (Landrace $\times$ Large White), em fase inicial de crescimento, com idade média de $48,71 \pm 3,97$ dias e peso inicial médio de $15,07 \pm 0,35 \mathrm{~kg}$, distribuídos em delineamento experimental de blocos ao acaso, com cinco tratamentos $(0,46,0,51,0,56,0,61$ e $0,65 \%$ de metionina + cistina digestível na ração), sete repetições e dois animais por unidade experimental, mantidos em ambiente termoneutro. Na formação dos blocos, levou-se em consideração o peso inicial e o parentesco dos animais.

Os animais, alojados em gaiolas metálicas, foram mantidos em salas climatizadas, com controle de temperatura e umidade relativa.

As condições ambientais no interior da sala foram monitoradas diariamente, três vezes ao dia (8, 12 e 18 horas), por meio de termômetro de bulbo seco e bulbo úmido, termômetros de máxima e mínima e termômetro de globo negro. Posteriormente, os valores registrados de temperatura de globo e umidade relativa do ar foram convertidos em índice de temperatura de globo e umidade (ITGU), segundo Buffington et al. (1981), caracterizando o ambiente ao qual os animais foram submetidos.

As dietas experimentais, isoenergética e isolisínica, formuladas à base de milho, farelo de soja e sorgo, foram suplementadas com minerais, vitaminas e aminoácidos, de acordo com as recomendações contidas em Rostagno et al. (2000), com exceção da metionina e cistina. Os tratamentos que consistiram de diferentes níveis de metionina + cistina nas rações foram obtidos a partir da inclusão de DL-metionina $99 \%$, em substituição ao ácido glutâmico. Ração experimental e água foram fornecidas à vontade. As composições centesimal e calculada das dietas experimentais são apresentadas na Tab. 1 . 
Tabela 1. Composição centesimal e calculada das rações experimentais para suínos dos 15 aos $30 \mathrm{~kg}$ de peso

\begin{tabular}{|c|c|c|c|c|c|}
\hline \multirow{2}{*}{ Ingrediente } & \multicolumn{5}{|c|}{ Níveis de Metionina + cistina digestível } \\
\hline & 0,46 & 0,51 & 0,56 & 0,61 & 0,65 \\
\hline Milho & 41,727 & 41,727 & 41,727 & 41,727 & 41,727 \\
\hline Farelo soja & 20,700 & 20,700 & 20,700 & 20,700 & 20,700 \\
\hline Sorgo & 31,000 & 31,000 & 31,000 & 31,000 & 31,000 \\
\hline Óleo de soja & 2,400 & 2,400 & 2,400 & 2,400 & 2,400 \\
\hline Fosfato bicálcico & 1,780 & 1,780 & 1,780 & 1,780 & 1,780 \\
\hline Calcário & 0,853 & 0,853 & 0,853 & 0,853 & 0,853 \\
\hline Mistura mineral $^{1}$ & 0,100 & 0,100 & 0,100 & 0,100 & 0,100 \\
\hline Mistura vitamínica $^{2}$ & 0,100 & 0,100 & 0,100 & 0,100 & 0,100 \\
\hline Sal comum & 0,360 & 0,360 & 0,360 & 0,360 & 0,360 \\
\hline BHT & 0,010 & 0,010 & 0,010 & 0,010 & 0,010 \\
\hline L-Lisina $\mathrm{HCl}$ & 0,359 & 0,359 & 0,359 & 0,359 & 0,359 \\
\hline DL-Metionina & 0,000 & 0,047 & 0,094 & 0,142 & 0,189 \\
\hline L-Treonina & 0,099 & 0,099 & 0,099 & 0,099 & 0,099 \\
\hline L-Triptofano & 0,012 & 0,012 & 0,012 & 0,012 & 0,012 \\
\hline Ácido glutâmico & 0,500 & 0,453 & 0,406 & 0,358 & 0,311 \\
\hline Total & 100,00 & 100,00 & 100,00 & 100,00 & 100,00 \\
\hline \multicolumn{6}{|c|}{ Composição calculada ${ }^{3}$} \\
\hline Proteína bruta (\%) & 16,118 & 16,118 & 16,118 & 16,118 & 16,118 \\
\hline Energia digestível (kcal/kg) & 3.400 & 3.400 & 3.400 & 3.400 & 3.400 \\
\hline Lisina total $(\%)$ & 1,029 & 1,029 & 1,029 & 1,029 & 1,029 \\
\hline Lisina digestível (\%) & 0,930 & 0,930 & 0,930 & 0,930 & 0,930 \\
\hline Met+Cis digestível (\%) & 0,465 & 0,511 & 0,558 & 0,605 & 0,652 \\
\hline Treonina digestível (\%) & 0,614 & 0,614 & 0,614 & 0,614 & 0,614 \\
\hline Triptofano digestível (\%) & 0,177 & 0,177 & 0,177 & 0,177 & 0,177 \\
\hline Cálcio (\%) & 0,830 & 0,830 & 0,830 & 0,830 & 0,830 \\
\hline Fósforo total (\%) & 0,635 & 0,635 & 0,635 & 0,635 & 0,635 \\
\hline Fósforo disponível (\%) & 0,430 & 0,430 & 0,430 & 0,430 & 0,430 \\
\hline Sódio (\%) & 0,180 & 0,180 & 0,180 & 0,180 & 0,180 \\
\hline Rel. met+cis dig:Lis digestível (\%) & 50 & 55 & 60 & 65 & 70 \\
\hline
\end{tabular}

As análises bromatológicas dos ingredientes foram realizadas conforme técnicas descritas por Silva (1990).

Durante o período experimental, as sobras de ração e os animais foram pesados a cada 10 dias para avaliação do consumo de ração, conversão alimentar e ganho de peso. No final do período experimental, quando atingiram o peso final de $29,95 \pm 0,43 \mathrm{~kg}$, os animais foram submetidos a jejum alimentar por 24 horas, após o qual um animal de cada unidade experimental foi abatido, por dessensibilização e sangramento, e dele retiradas as vísceras.

A carcaça inteira (incluindo cabeça e pés), eviscerada e sem sangue, foi pesada e cortada longitudinalmente. A metade direita foi triturada em cutter comercial de 30 HP e 1.775 revoluções por minuto. Após homogeneização, amostras foram retiradas e congeladas para determinação da deposição de proteína e gordura, conforme metodologia descrita por Donzele et al. (1992). Para determinação da composição da carcaça, um grupo adicional de cinco leitões, com peso médio de $15 \mathrm{~kg}$, foi abatido no início do experimento, seguindo o mesmo procedimento de abate adotado para os animais utilizados no experimento.

No preparo das amostras, em razão do alto teor de gordura do material, procedeu-se à présecagem em estufa, com ventilação forçada a $60^{\circ} \mathrm{C}$, por 72 horas, e ao pré-desengorduramento, a quente, em aparelho extrator do tipo Soxhlet, por quatro horas. As amostras pré-secas e pré- 
desengorduradas foram moídas e acondicionadas em vidros para posteriores análises de laboratório. Para correção dos valores das análises subseqüentes, foram consideradas a água e a gordura retiradas no preparo das amostras.

As análises de proteína bruta e extrato etéreo das carcaças foram realizadas conforme técnicas descritas por Silva (1990).

Os valores da composição das carcaças dos leitões, no início e no fim do período experimental, foram utilizados para a determinação das deposições de proteína e gordura e da energia digestível retida na carcaça.

A porcentagem de energia digestível retida na carcaça por dia foi calculada como a razão entre a energia retida como proteína $(5,69 \mathrm{kCal} / \mathrm{gN}$ x $6,25)$ e a energia digestível total retida na carcaça. A energia total retida na carcaça foi calculada, utilizando-se os fatores de conversão de acordo com Quiniou et al. (1996), sendo igual ao somatório da energia retida como gordura $(9,49 \mathrm{kcal} / \mathrm{g})$ e da energia retida como proteína $(5,69 \mathrm{kcal} / \mathrm{gN} \times 6,25)$.

As análises estatísticas das variáveis de desempenho (ganho de peso, consumo de ração e conversão alimentar) e de deposição de proteína e gordura na carcaça foram realizadas utilizandose o programa ANOVAG contido no pacote computacional SAEG (Sistema..., 1997).

A estimativa da exigência de aminoácidos sulfurados digestíveis foi determinada com base nos resultados de desempenho e carcaça utilizando os modelos linear, quadrático, ou descontínuo linear response plateau (LRP) descritos por Braga (1983), conforme o melhor ajuste obtido para cada variável.

\section{RESULTADOS E DISCUSSÃO}

A temperatura interna da sala manteve-se, durante o período experimental, em $21,8 \pm 0,4^{\circ} \mathrm{C}$, a umidade relativa em $73,8 \pm 4,9$ e a temperatura de globo negro em $22,3 \pm 0,4^{\circ} \mathrm{C}$. O ITGU calculado no período foi de $69,5 \pm 0,5$. A temperatura interna obtida pode ser estabelecida como a de conforto por estar na faixa considerada ideal $\left(18-22^{\circ} \mathrm{C}\right)$ para essa categoria animal, segundo Curtis (1983), e o valor de ITGU, que definiu o ambiente termoneutro, foi similar àquele que caracterizou o ambiente de conforto no estudo conduzido por Ferreira (2001), com suínos de 15 a 30kg.

Os resultados de desempenho, consumo de metionina + cistina digestível, porcentagem de energia digestível retida como proteína na carcaça por dia (EDPtn) e de deposições de proteína e de gordura na carcaça dos suínos encontram-se na Tab. 2.

Os níveis de metionina + cistina digestível da ração influenciaram $(\mathrm{P}<0,05)$ o ganho de peso diário (GPD), que variou de forma quadrática, aumentando até o nível de $0,60 \%$ (Fig. 1). Esses resultados estão acima do nível de $0,52 \%$ de aminoácidos sulfurados digestíveis proposto por Chung e Baker (1992), como a exigência de suínos de 5 a $20 \mathrm{~kg}$ mantidos em ambiente termoneutro.

Tabela 2. Resultados de desempenho, consumo de metionina + cistina digestível, porcentagem de energia digestível retida como proteína na carcaça por dia (EDPtn) e de deposições de proteína e de gordura de suínos machos castrados, mantidos em ambiente de termoneutralidade, dos 15 aos $30 \mathrm{~kg}$

\begin{tabular}{lcccccc}
\hline \multirow{2}{*}{ Variável } & \multicolumn{3}{c}{ Nível de metionina + cistina digestível (\%) } & CV\% \\
\cline { 2 - 7 } & 0,465 & 0,511 & 0,558 & 0,605 & 0,652 & \\
\hline Ganho de peso (g/dia) & 583 & 640 & 670 & 672 & 661 & 7,32 \\
Consumo de ração (g/dia) $_{\text {Consumo de met+cis dig (g/dia) }}{ }^{2}$ & 1115 & 1144 & 1196 & 1142 & 1149 & 7,72 \\
Conversão alimentar (g/g) $^{3}$ & 5,18 & 5,85 & 6,68 & 6,91 & 7,49 & 7,55 \\
EDPtn (g/dia) & 1,92 & 1,79 & 1,79 & 1,70 & 1,72 & 4,17 \\
& 24,77 & 28,01 & 29,21 & 30,03 & 29,63 & 7,61 \\
Proteína (g/dia) & Deposição na carcaça & 70 & 77 & 77 & 80 & 11,97 \\
Gordura (g/dia) & 59 & 70 & 113 & 108 & 115 & 10,39 \\
\hline
\end{tabular}

1 e $3=$ efeito quadrático $(\mathrm{P}<0,05)$ e $(\mathrm{P}<0,10)$, respectivamente.

$2=$ efeito linear $(\mathrm{P}<0,05)$. 


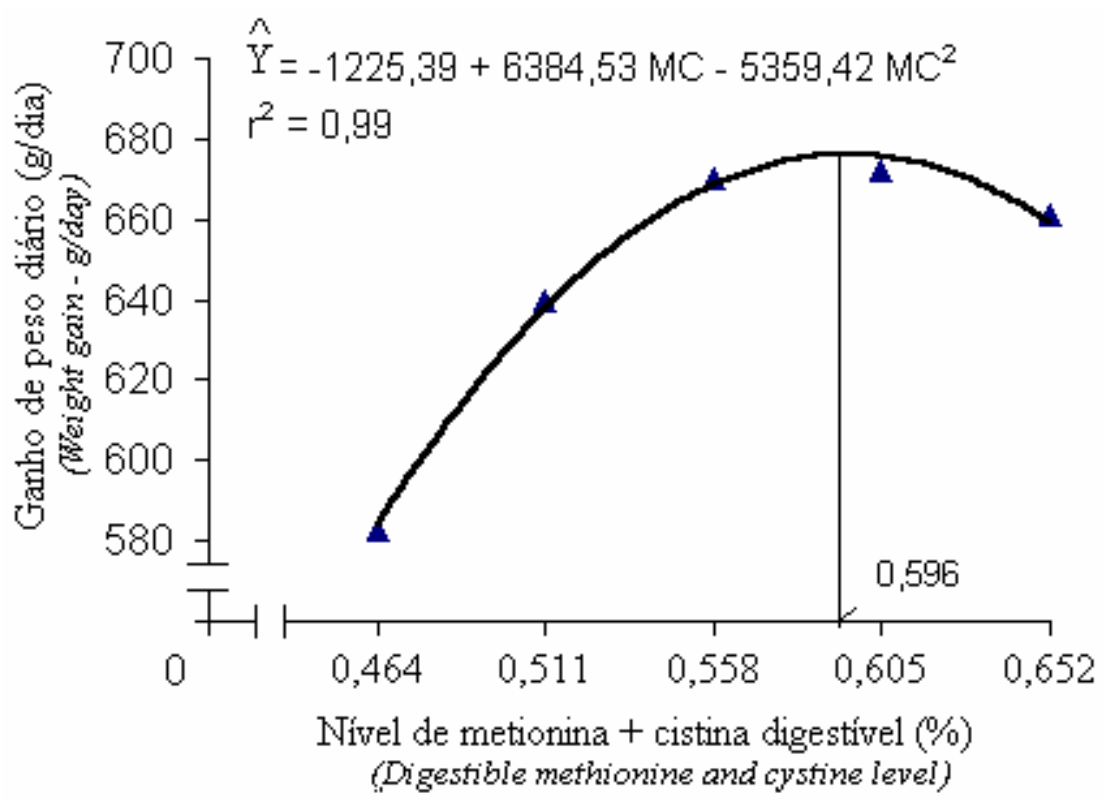

Figura 1. Ganho de peso diário em função dos níveis de metionina + cistina digestível das dietas de leitões machos castrados, mantidos em ambiente de termoneutralidade, dos 15 aos $30 \mathrm{~kg}$.

Aumento no GPD de suínos na fase inicial de crescimento, em razão da suplementação de metionina + cistina digestível na ração, também foi observado por Leibholz $(1984 ; 1985)$.

A diferença dos resultados obtidos pode estar relacionada, entre outros fatores, aos níveis de lisina e aminoácidos sulfurados digestíveis utilizados na ração basal. Segundo Friesen et al. (1994), o excesso de cistina utilizado pode influenciar a resposta de ganho de peso dos animais com relação ao nível de metionina.

O aumento no ganho de peso ocorrido entre os níveis 0,46 a $0,60 \%$ de aminoácidos sulfurados digestíveis estaria indicando que houve melhora gradativa no balanço aminoacídico da ração, resultando na relação aminoácido sulfurado digestível:lisina digestível de $64 \%$ no nível de melhor resposta.

Apesar da evidência apresentada pelos resultados de GPD, de que provavelmente tenha ocorrido balanço inadequado de aminoácidos nas dietas em alguns dos níveis de metionina + cistina digestível, este não foi suficiente para influenciar $(\mathrm{P}>0,10)$ o consumo de ração diário (CRD). De acordo com Henry e Séve (1993), dietas com limitação de metionina podem influenciar negativamente o consumo voluntário dos animais.

Os resultados de consumo obtidos foram semelhantes aos observados por Moita (1994), que avaliaram níveis de aminoácidos sulfurados para leitões recém-desmamados.

Por não ter ocorrido variação no $\mathrm{CRD}$ entre os tratamentos, foi constatado aumento linear $(\mathrm{P}<0,05)$ no consumo de metionina + cistina digestível em função dos níveis na dieta, conforme a equação: $\hat{Y}=-0,359853+$ $12,1356 \mathrm{X}$.

Foi observado efeito $(\mathrm{P}<0,10)$ dos tratamentos sobre a conversão alimentar (CA), que melhorou de forma quadrática até o nível estimado de $0,63 \%$ (Fig. 2), correspondendo à relação aminoácidos sulfurados digestível:lisina digestível de $67 \%$. Os resultados obtidos neste estudo assemelham-se aos de Chung e Baker (1992) e Moita (1994) que também observaram efeito positivo da suplementação de metionina sobre a CA dos leitões na fase inicial de crescimento, muito embora ocorressem discrepâncias entre os níveis de metionina, nos quais foram obtidos os melhores resultados. 


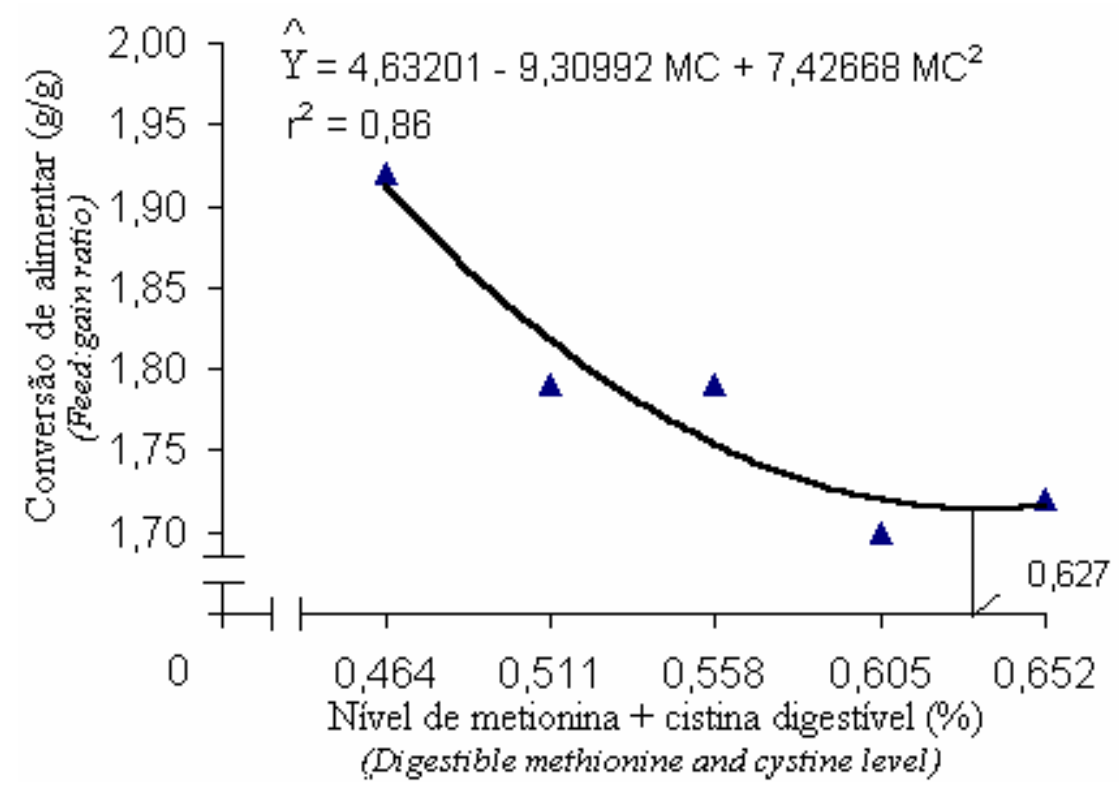

Figura 2. Conversão alimentar em função dos níveis de metionina + cistina digestível das dietas de leitões machos castrados, mantidos em ambiente de termoneutralidade, dos 15 aos $30 \mathrm{~kg}$.

Variações observadas entre os resultados obtidos em diferentes trabalhos podem estar associadas a fatores como a genética e o sexo dos animais, a composição da dieta experimental, dentre outros. Com relação à composição da dieta, Kroening et al. (1965) constataram que a exigência de aminoácidos sulfurados alterou de 0,50 para $0,70 \%$ quando o nível de proteína da dieta aumentou de 12 para $25 \%$.

Neste estudo, ficou caracterizado que a relação ideal entre aminoácidos sulfurados digestíveis:lisina digestível para melhor resposta de conversão alimentar é superior àquela para melhor resposta de ganho de peso. Esse relato é consistente com os resultados obtidos por Loughmiller et al. (1996) que, ao avaliarem a exigência de metionina para suínos em terminação, constataram que somente a $\mathrm{CA}$ foi influenciada pelo nível desse aminoácido na ração.

As relações de metionina + cistina digestível:lisina digestível que promoveram os melhores resultados de ganho de peso (64\%) e conversão alimentar (67\%), verificadas no presente estudo, estão acima daquela de $60 \%$ proposta por Chung e Baker (1992) e por Rostagno (2000).

A porcentagem de energia digestível retida como proteína na carcaça (EDPtn) variou de forma quadrática $(\mathrm{P}<0,05)$, aumentando até o nível de $0,61 \%$ na ração (Fig. 3), correspondente a uma relação de metionina + cistina digestível:lisina digestível de $65 \%$.

A deposição de proteína (DP) na carcaça atingiu o ponto máximo $(\mathrm{P}<0,05)$ no nível estimado de $0,63 \%$ (Fig. 4), que correspondeu à relação metionina + cistina digestível:lisina digestível de $68 \%$. Efeito positivo do nível de aminoácidos sulfurados da ração sobre a DP na carcaça de suínos também foi observado por Grandhi e Nyachoti (2002). Com esses resultados ficou evidente que a demanda de aminoácidos sulfurados para DP na carcaça é maior que aquela para GPD. 


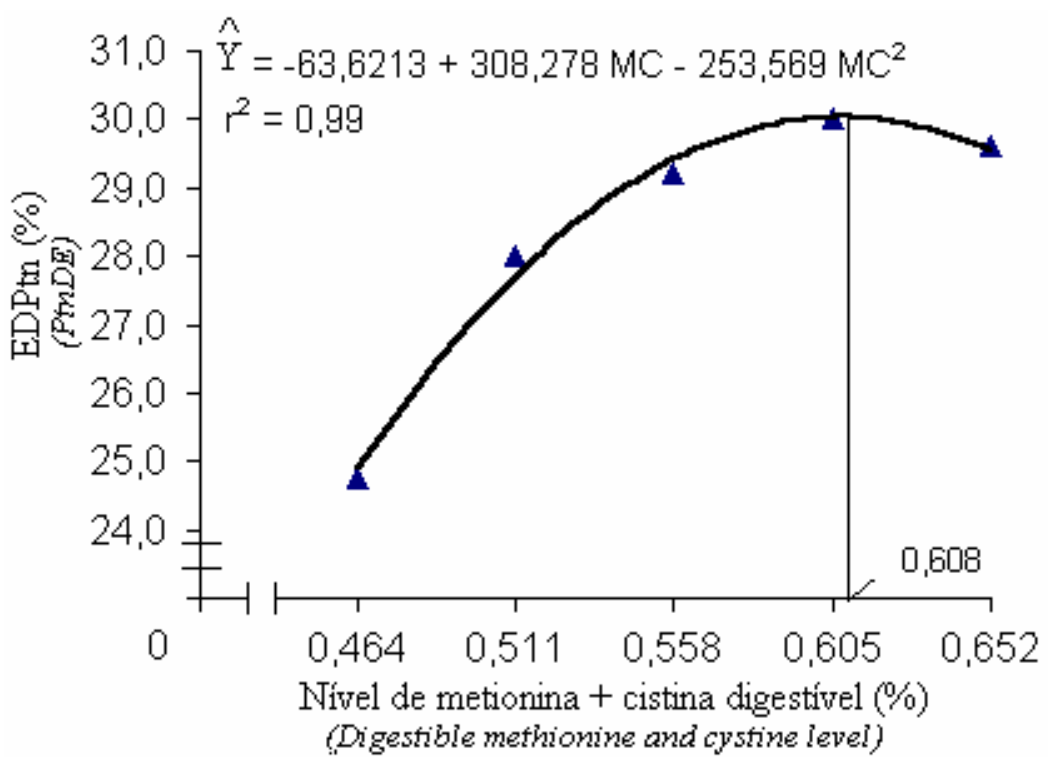

Figura 3. Porcentagem de energia digestível retida como proteína na carcaça (EDPtn) em função dos níveis de metionina + cistina digestível das dietas de leitões machos castrados, mantidos em ambiente de termoneutralidade, dos 15 aos $30 \mathrm{~kg}$.

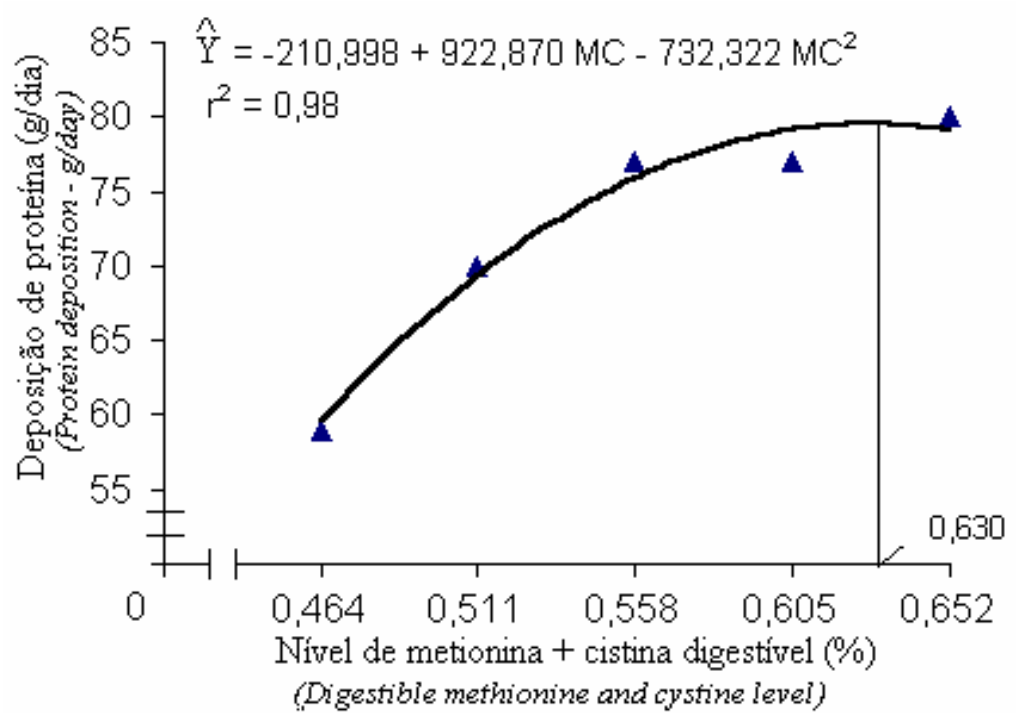

Figura 4. Deposição de proteína na carcaça em função dos níveis de metionina + cistina digestível das dietas de leitões machos castrados, mantidos em ambiente de termoneutralidade, dos 15 aos $30 \mathrm{~kg}$.

Tomando como base o fato de que a deposição de proteína, por agregar maior quantidade de água, é mais eficiente que a de gordura (Kyriazakis et al., 1994), o aumento na DP na carcaça justifica a melhora observada na conversão alimentar.
Os resultados indicam que o fornecimento de dieta com proteína bem balanceada é essencial para otimizar a deposição de proteína na carcaça, e que os leitões nessa fase de crescimento exigem maior nível de aminoácidos sulfurados na dieta para maximizar a deposição de proteína que aquele exigido para maior ganho de peso. 
Não se observou efeito $(\mathrm{P}>0,10)$ dos tratamentos sobre a deposição de gordura na carcaça, confirmando os resultados obtidos por Moita (1994), Friesen et al. (1994) e Grandhi e Nyachoti (2002).

\section{CONCLUSÃO}

Suínos machos castrados, mantidos em ambiente termoneutro, dos 15 aos $30 \mathrm{~kg}$, exigem, para melhor desempenho e composição da carcaça, $0,63 \%$ de aminoácidos sulfurados digestíveis na dieta, correspondente à relação de $67 \%$ de metionina + cistina digestível:lisina digestível.

\section{REFERÊNCIAS BIBLIOGRÁFICAS}

BRAGA, J.M. Avaliação da fertilidade do solo; ensaios de campo. Viçosa-MG, 1983. 101p.

BUFFINGTON, D.E.; COLAZZO-AROCHO, A.; CANTON, G.H. et al. Black globe-humidity index (BGHI) as comfort equation for dairy cows. Trans. $A S A E$, v.24, p.711-714, 1981.

CHUNG, T.K.; BAKER, D.H. Methionine requirement of pigs between 5 and 20 kilograms body weight. J. Anim. Sci., v.70, p.1857-1863, 1992.

CURTIS, S.E., Environmental management in animal agriculture. Iowa State University, 1983. 409p.

DONZELE, J.L.; COSTA, P.M.A.; ROSTAGNO, H.S. et al. Efeitos de níveis de energia digestíveis na composição da carcaça de suínos de cinco a quinze quilos. Rev. Soc. Bras. Zootec., v.21, p.1100-1106, 1992.

EFFECT of environmental on nutrient requirements of domestic animals. Washington, DC: NRC, NAS, 1981. $52 \mathrm{p}$.

FERREIRA, F.A. Avaliação da redução da proteína bruta com suplementação de aminoácidos para suínos de 15 a $60 \mathrm{~kg}$ mantidos em diferentes ambientes térmicos. 2001. 67f. Tese (Doutorado em Zootecnia) Universidade Federal de Viçosa, Viçosa, MG.

GRANDHI, R.R.; NYACHOTI, C.M. Effect of true ileal digestible dietary methionine to lysine ratios on growth performance and carcass merit of boars, gilts and barrows selected for low backfat. Can. J. Anim. Sci., v.82, p.399-407, 2002.

HEDGES, J.D. 2003. Environmentally friendly formulation. Swine. Disponível em:
$<$ http://hubbardfeeds.com/nmg/swine/swine envirofrie ndly.shtml $>$. Acessado em 10 janeiro 2003, p.1-2.

HENRY, Y.; SÈVE, B. Feed intake and dietary aminoacid balance in growing pigs with special reference to lysine, tryptophan and threonine. Pig News Inf., v.14, n.1, 1993.

KEER, B.J.; EASTER, R.A. Effect of feeding reduced protein, amino acid-supplemented diets on nitrogen and energy balance in grower pigs. J. Anim. Sci., v.73, p.3000-3008, 1995.

KROENING, G.H.; POND, W.G.; LOOSLI, J.K. Dietary methionine-cystine requirement of baby pig as affected by threonine and protein levels. J. Anim. Sci., v.4. p.519-526, 1965

KYRIAZAKIS, I.; DOTAS, D.; EMMANS, G.C. The effects of breed on the relatonship between feed composition and the efficiency of protein utilization in pigs. Br. J. Nutr., v.71, p.849-859, 1994.

LEIBHOLZ. J. A note on the influence of methionine content in the diet of pigs from 21 to 49 days of age on their performance from 49 to 97 days of age. Anim. Prod., v.39, p.153-159, 1984.

LEIBHOLZ. J. The digestion of protein in young pigs and the utilization of dietary methionine. Br. J. Nutr., v.53, p.391-397, 1985.

LEWIS, A.J. Amino acids in swine nutrition. In: MILLER, E.R.; ULLREY, D.E.; LEWIS, A.J. Swine nutrition. Butterworth-Heinemann, 1991. p.147-164.

LOUGHMILLER, J.A.; TOKACH, M.D.; GOODBAND, R.D. et al. Dietary total sulfur aminoacid requirement for optimal growth performance and carcass characteristics in finishing gilts. Swine Day, p.133135, 1996.

MOITA, A.M.S. Exigência de proteína, lisina, metionina e cistina e níveis de energia digestível para leitões de 12 a 28 dias de idade. 1994. 100f. Tese (Doutorado em Zootecnia) - Universidade Federal de Viçosa, Viçosa, MG.

QUINIOU, N.; DOURMAD, J.Y.; NOBLET, J. Effect of energy intake on the performance of different types of pig from 45 to $100 \mathrm{~kg}$ body weight. 1. Protein and lipid deposition. J. Anim. Sci., v.63, p.227-288,1996.

ROSTAGNO, H.S.; ALBINO, L.F.T.; DONZELE, J.L. et al. Composição de alimentos e exigências nutricionais de aves e suinos: Tabelas Brasileiras. Viçosa, MG:UFV, 2000. 141p.

SILVA, D.J. Análise de alimentos: métodos químicos e biológicos. Viçosa, MG: UFV, 1990. 166p.

SISTEMA de análíses estatísticas e genéticas - SAEG. Viçosa: UFV, 1995. 150p. 